\title{
PRIMEIRA OCORRÊNCIA DE PHELLINUS MANGROVICUS (IMAZ.) IMAZ. PARA O BRASIL ${ }^{1}$
}

\author{
Ezequias Lopes de Campos ${ }^{2}$ \\ Maria Auxiliadora Queiroz Cavalcanti ${ }^{2}$
}

Recebido em 04/02/2000. Aceito em 27/04/2000

\begin{abstract}
RESUMO - (Primeira ocorrência de Phellinus mangrovicus (Imaz.) Imaz. para o Brasil). Phellinus mangrovicus (Imaz.) Imaz. foi coletado em manguezais da Ilha de Algodoal-Maiandeua, no litoral do Pará, em maio/1999, sobre tronco em decomposição de Rhizophora mangle L., constituindo este o primeiro registro da espécie para o Brasil.
\end{abstract}

Palavras-chave - Phellinus mangrovicus, Hymenochaetaceae, manguezais, Brasil

ABSTRACT - (First record of Phellinus mangrovicus (Imaz.) Imaz. from Brazil). Phellinus mangrovicus (Imaz.) Imaz. was collected in mangroves of the Algodoal-Maiandeua Island, Pará, Brazil, in May/1999, on bark of Rhizophora mangle L. in decomposition, this constituting the first record of the species from Brazil.

Key words - Phellinus mangrovicus, Hymenochaetaceae, mangroves, Brazil

\section{Introdução}

O ecossistema manguezal apresenta ampla distribuição geográfica no Brasil, ocupando grande parte de seu litoral (Sant'Anna \& Whately 1981). Apesar de sua extensão e importância, este ecossistema é ambiente pouco explorado em relação à micota, porém, nos poucos trabalhos envolvendo fungos macroscópicos, considerando a baixa diversidade de fungos neste ambiente (Goh \& Yipp 1996), o gênero Phellinus é relativamente bem representado. Até o presente, foram citados $P$. mangrovicus (Imazeki 1941), P. pachyphloeus (Fidalgo 1968), P. gilvus (Kohlmeyer 1969; Sotão et al. 1991; Almeida-Filho et al. 1993), P. rimosus (Bononi 1984) e P. punctatus (Sotão et al. 1991). Este trabalho tem como objetivo relatar a segunda ocorrência ao nível mundial de $P$. mangrovicus, tendo em vista que o único registro até o momento foi citado para o Japão, por Imazeki (1941).

\section{Material e métodos}

A Ilha de Algodoal-Maiandeua situa-se no litoral nordeste do Estado do Pará, no município de Maracanã, entre as coordenadas geográfi-

\footnotetext{
1 Parte da Dissertação de Mestrado do primeiro autor

2 Departamento de Micologia, Universidade Federal de Pernambuco, Rua Prof. Nelson Chaves s/n, CEP 50760-420, Recife, PE, Brasil
} 
cas de $00^{\circ} 35^{\prime} 03^{\prime \prime}$ a $00^{\circ} 38^{\prime} 29^{\prime \prime}$ s e $47^{\circ} 31^{\prime} 54^{\prime \prime}$ a 4734'57'W e possui área de 2.378 ha (Bastos 1996).

A espécie, dentre outras dezenove estudadas, foi coletada em manguezais da Ilha de Algodoal-Maiandeua-PA em maio/1999.

No campo, os espécimes foram coletados manualmente com auxílio de uma faca e acondicionados em sacos de papel. No laboratório, foram feitas anotações relativas à cor das superfícies abhimenial e himenial, do contexto, dos tubos e da margem, utilizando-se a carta de cores de Maerz \& Paul (1950), e anotações relativas à espessura, comprimento e largura do basidioma. Na preservação e herborização seguiu-se Fidalgo \& Bononi (1984).

Para a observação microscópica do material, foram feitos cortes à mão livre dos basidiomas com lâminas de aço inixodável. Os cortes foram acondicionados em lâminas de vidro contendo hidróxido de potássio $3 \%$ e corados com floxina $1 \%$, segundo a técnica de Martin (1934). Também foi utilizado o reagente de Melzer, segundo Singer (1951), para observação da reação amilóide ou dextrinóide dos basidiosporos, hifas e outras microestruturas.

Os espécimes foram depositados no Herbário "Padre Camilo Torrend" (URM) do Departamento de Micologia da Universidade Federal de Pernambuco (UFPE).

\section{Resultados e discussão}

Phellinus mangrovicus (Imaz.) Imaz., Bull. Forest Exp. Sta. Meguro 57: 114. 1952.

Basiônimo: Fomes mangrovicus Imaz., J. Jap. Bot. 17: 176. 1941.

(Fig. 1)

Basidioma anual, séssil, 1,8-9,0 x 1,4-5,8 x 1,3-5,3cm. Píleo conchado, imbricado, lenhoso. Superfície abhimenial glabra a velutina, zonada, profundamente sulcada, MP16A12 (Biskra Date), MP16C10, MP16C8, MP16H9. Margem lobada, inteira, marrom MP16A12 (Biskra Date). Contexto duplex com uma linha preta fina a espessa bem distinta, concolor com a margem, 0,2-0,3 cm espesso. Superfície himenial poróide com poros circulares a angulares, ferrugínea MP12H6 (Roe), MP12E5 (Indian Buff), MP12I5, 5-6 poros por $\mathrm{mm}$. Sistema hifálico dimítico; hifas generativas septadas, sem ansas, hialinas a levemente amareladas, parede fina, 2,5-5,0mm diâm.; hifas esqueléteas castanhas, não ramificadas, tortuosas, parede espessa, 3,06,0mm diâm. Cistídios e setas ausentes. Basídios não observados. Basidiosporos castanhos, muito numerosos, parede espessa, lisa, ocasionalmente unigutulados, contendo em seu interior uma substância refringente, 5,0-6,5 x 5,0mm.

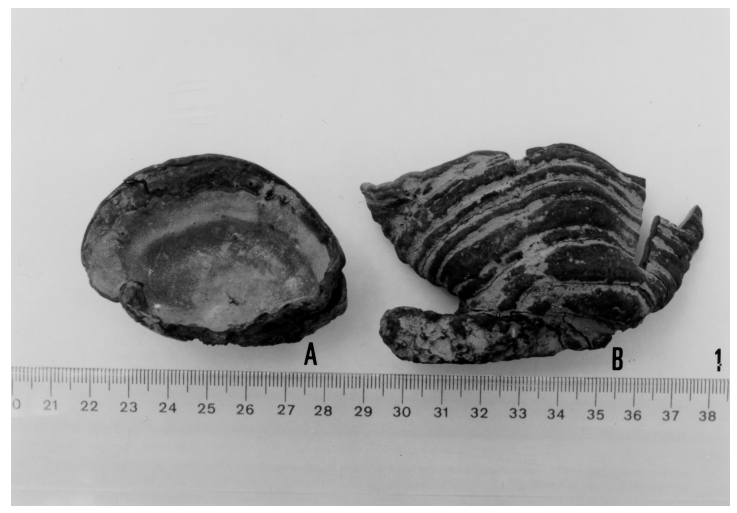

Figura 1. Basidiomas de Phellinus mangrovicus. a) superfície himenial e b) superfície abhimenial.

Espécime estudado: BRASIL, Pará: Maracanã, Manguezal da Ilha de AlgodoalMaiandeua, sobre Rhizophora mangle em decomposição, Campos \& Luz XII/1998 (URM 76928).

Distribuição: Kusai, Japão (Imazeki 1941), sendo atualmente ampliada para o Brasil.

Os basidiosporos desta espécie possuem as mesmas características dos basidiosporos de Phellinus fastuosus (Lév.) Ryv., porém diferenciam-se desta última por apresentar parede ligeiramente mais espessada. Outra diferença marcante da espécie é a presença de uma linha preta dividindo o contexto, além de sulcos profundos na superfície abhimenial. De acordo com a literatura consultada, aparentemente trata-se da primeira citação fora do Japão. Imazeki 
(1941) descreveu esta espécie sobre Rhizophora mangle em Kusai, no Japão, sob a denominação de Fomes mangrovicus. Posteriormente, o mesmo autor transferiu o táxon para o gênero Phellinus, como P. mangrovicus (Imazeki 1952). A espécie pode ser considerada de ocorrência rara, visto que, nas coletas realizadas em quatro diferentes períodos, foi somente detectada em um período (maio/1999), sobre tronco de Rhizophora mangle, coincidindo com o mesmo substrato da espécie descrita originalmente por Imazeki (1941) no Japão. Larsen \& Cobb-Poulle (1990), na revisão do gênero Phellinus, consideram P. mangrovicus restrita à localidade-tipo (Kusai, Japão). As características microscópicas estão de acordo com as da espécie descrita para o Japão por Imazeki (1941). Entretanto, não há qualquer referência quanto à presença ou ausência da linha preta no contexto.

\section{Agradecimentos}

Os autores agradecem ao Departamento de Micologia da Universidade Federal de Pernambuco pelo apoio e facilidades oferecidas; à MSc. Tatiana Gibertoni, pelo auxílio na identificação do material; à Coordenação de Aperfeiçoamento de Pessoal de Nível Superior (CAPES), pela concessão de bolsa de Mestrado ao primeiro autor.

\section{Referências bibliográficas}

Almeida Filho, O. M.; Bueno, R \& Bononi, V. L. 1993. Algumas espécies de fungos Basidiomycetes de manguezais do Estado de São Paulo. Hoehnea 20 (1/2): 87-92.

Bastos, M. N. C. 1996. Caracterização das formações vegetais da restinga da praia da Princesa, Algodoal-Maiandeua - PA. Tese de Doutorado. Universidade Federal do Pará/Museu Paraense Emílio Goeldi, Belém.

Bononi, V. L. 1984. Basidiomycetes do Parque Estadual da Ilha do Cardoso: IV. Adições às famílias Hymenochataceae, Stereaceae e Thelephoraceae.

Rickia 11: 43-52.
Fidalgo, O. 1968. Phellinus pachyphloeus and its allies. Memoirs of the New York Botanical Garden 17(2): 109-147.

Fidalgo, O. \& Bononi, V. L. 1984. (Coord.). Técnicas de coleta, preservação e herborização de material botânico. Instituto de Botânica, São Paulo. (Manual n. 4).

Goh, T. K. \& Yipp, M. W. 1996. "In vivo" and "in vitro" studies of three new species of Trimmastostroma associated with sooty spots of the mangrove Aegiceras corniculatum in HongKong. Mycological Research 100(12): 1489-1497.

Imazeki, R. 1941. Materials of the Micronesian higher fungi. Journal Japanese of Botany 17: 175-184.

Imazeki, R. 1952. A contribution to the fungous flora of Dutch New Guinea. Bulletin Forest Experimental Station of the Meguro 57: 87-128.

Kohlmeyer, J. 1969. Ecological notes on fungi in mangrove forests. Transactions of the Britsh Mycological Society 53(2): 237-250.

Larsen, M. \& Cobb-Poule, L. A. 1990. Phellinus (Hymenochaetaceae). A survey of the world taxa Synopsis Fungorum n. 3, Oslo.

Maerz, A. \& Paul, M. R. 1950. A dictionary of colour. McGraw-Hill Book Company, 2a ed., New York.

Martin, C. G. 1934. Three new Heterobasidiomycetes. Mycologia 26: 261-265.

Sant'Anna, E. M. \& Whately, M. H. 1981. Distribuição dos manguezais do Brasil. Revista Brasileira de Geografia 43(1): 47-63

Sotão, H. M. P.; Bononi, L. R. \& Figueredo, T. 1991. Basidiomycetes de manguezais da Ilha de Maracá. Amapá. Boletim do Museu Paraense Emílio Goeldi, série Botânica 7: 109-114.

Singer, R. 1951. The Agaricales (mushrooms) in modern taxonomy. Lilloa, Tucumán. 